\title{
Effect of High-Flow Nasal Cannula on Expiratory Pressure and Ventilation in Infant, Pediatric, and Adult Models
}

\author{
Katie R Nielsen MD MPH, Laura E Ellington MD, Alan J Gray, Larissa I Stanberry PhD, \\ Lincoln S Smith MD, and Robert M DiBlasi RRT-NPS FAARC
}

\begin{abstract}
BACKGROUND: Heated and humidified high-flow nasal cannula (HFNC) is a widely used form of respiratory support; however, data regarding optimal flows for a given patient size or disease state are lacking. A comprehensive study of the physiologic effects of HFNC is needed to better understand the mechanisms of action. The objective of the current study was to quantify the effect of HFNC settings in age-specific, anatomically correct nasal airways and spontaneously breathing lung models. We hypothesized that there is an effect of flow on pressure and ventilation. METHODS: Three-dimensionally printed upper airway models of a preterm neonate, term neonate, toddler, small child, and adult were affixed to the ASL 5000 test lung to simulate spontaneous breathing with age-appropriate normal ventilation parameters. $\mathrm{CO}_{2}$ was introduced to simulate profound hypercapneic respiratory failure with an end-tidal partial pressure of carbon dioxide $\left(\mathrm{P}_{\mathbf{E T C O}}\right)$ of $90 \pm 1 \mathrm{~mm} \mathrm{Hg}$. Two commercially available HFNC systems were applied to the airway models, and PEEP, inspired $\mathrm{CO}_{2}$, and exhaled $\mathrm{CO}_{2}\left(\mathrm{P}_{\mathrm{ETCO}_{2}}\right)$ were recorded for 6 min across a range of flow. RESULTS: Increasing HFNC flow provided a non-linear increase in PEEP in closed-mouth models, with maximum tested flows generating $6 \mathrm{~cm} \mathrm{H}_{2} \mathrm{O}$ in the preterm neonate to $20 \mathrm{~cm}_{2} \mathrm{O}$ in the small child. Importantly, PEEP decreased by approximately 50\% in open-mouth models. Increasing HFNC flow improved expiratory $\mathrm{CO}_{2}$ elimination to a certain point, above which continued increases in flow had minimal additional effect. This change point ranged from $4 \mathrm{~L} / \mathrm{min}$ in the preterm neonate to $10 \mathrm{~L} / \mathrm{min}$ in the small child. CONCLUSIONS: These findings may help clinicians understand the effects of HFNC at different settings and may inform management guidelines for patients with respiratory failure. Key words: noninvasive ventilation; cannula; CPAP; respiratory dead space; ventilation; pediatric intensive care units. [Respir Care 2018;63(2):147-157. () 2018 Daedalus Enterprises]
\end{abstract}

\section{Introduction}

Heated and humidified high-flow nasal cannula (HFNC) was initially proposed as an alternative to CPAP for premature neonates. ${ }^{1}$ HFNC use has rapidly expanded to pa-

Drs Nielsen and Smith are affiliated with the Division of Critical Care Medicine, Department of Pediatrics, University of Washington, Seattle, Washington. Dr Ellington is affiliated with Graduate Medical Education, University of Washington, Seattle, Washington. Mr Gray is affiliated with the University of Washington School of Medicine, Seattle, Washington. Dr Stanberry and Mr DiBlasi are affiliated with the Seattle Children's Hospital and Research Institute, Seattle, Washington.

Mr DiBlasi has disclosed relationships with Draeger, Mallinckrodt, United Therapeutics, and Aerogen. The other authors have disclosed no conflicts of interest. tients with respiratory insufficiency, including infants with bronchiolitis $^{2}$ and adults with COPD ${ }^{3}$ and ARDS., ${ }^{4,5}$ Clinical studies suggest that HFNC effectively supports some patients who would have otherwise been treated with CPAP and noninvasive ventilation. ${ }^{5-7}$ However, there is a lack of experimental evidence to support widespread clinical implementation of HFNC.

\footnotetext{
Supplementary material related to this paper is available at http:// www.rcjournal.com.

Correspondence: Robert M DiBlasi RRT-NPS FAARC, Seattle Children's Research Institute, 1900 Ninth Ave North, Seattle, WA 98101. E-mail: robert.diblasi@seattlechildrens.org.
}

DOI: $10.4187 /$ respcare. 05728 
HFNC may improve oxygen delivery when flow exceeds peak inspiratory flow, thereby reducing air entrainment. ${ }^{8}$ Multiple studies suggest HFNC generates PEEP, improving alveolar recruitment and reducing airway obstruction. ${ }^{9-12}$ HFNC may also reduce minute ventilation demand by overcoming increased airway resistance $^{13}$ and flushing extrathoracic dead space, thereby reducing rebreathed exhaled $\mathrm{CO}_{2}{ }^{10,14,15}$ It is unclear which settings constitute HFNC therapy, and there is not consensus on initial flow for a given patient size, weaning, or indications for other forms of respiratory support. A comprehensive study of the physiologic effects of HFNC is needed to inform clinical management strategies and design future studies to better understand the mechanisms of action of HFNC.

The objective of the current study was to quantify the effect of HFNC settings in age-specific, anatomically correct nasal airways and spontaneously breathing lung models. We hypothesized that there is an effect of flow on pressure and ventilation.

\section{Methods}

\section{Nasal Airway and Lung Models}

Upper-airway models were constructed using 3-dimensional rapid prototyping devices from $\mathrm{CT}$ scans of the upper airways of a preterm neonate ( 28 weeks, $1 \mathrm{~kg}$ ), term neonate (38 weeks, $4 \mathrm{~kg}$ ), toddler (17 months, $10 \mathrm{~kg}$ ), small child $(5 \mathrm{y}, 20 \mathrm{~kg})$, and adult $(17 \mathrm{y}, 70 \mathrm{~kg}){ }^{16-18}$ Preterm and small child models had established oral airway openings, so open-mouth and closed-mouth conditions were simulated in these models. Term-neonate, toddler, and adult models did not have oral airway openings, so only closed-mouth conditions were simulated. Adapter, tubing, and pneumotachometer size were adjusted (quantified with water) to approximate previously published agespecific extrathoracic dead space values ${ }^{19}$ in all models except the preterm due to the minimum fixed volume of $\mathrm{CO}_{2}$ and pressure adaptors (Table 1 ).

Models were attached to the ASL 5000 Test Lung (Ingmar Medical, Pittsburgh, Pennsylvania) in series with a $\mathrm{CO}_{2}$ injection adapter, $\mathrm{CO}_{2}$ analyzer adapter, and pneumotachometer (Fig. 1). Spontaneous breathing was simulated using age-specific normal values. ${ }^{17,20-24}$ The inspiratory-to-expiratory ratio was held constant at $1: 3$, and inspiratory effort was adjusted to maintain constant tidal volume $(6 \mathrm{~mL} / \mathrm{kg})$ in each model at different HFNC flows. A $\mathrm{CO}_{2}$ injection port adapter with integrated unidirectional catheter was placed $5 \mathrm{~mm}$ within the lung model to preferentially direct $\mathrm{CO}_{2}$ flow to the lung compartment using a $\mathrm{CO}_{2}$ flow meter (Cole-Palmer, Vernon Hills, Illinois). $\mathrm{CO}_{2}$ was measured with a calibrated mainstream

\section{QUICK LOOK}

\section{Current knowledge}

High-flow nasal cannula (HFNC) is increasingly being used as an intermediary form of noninvasive support. Studies have shown that HFNC may improve oxygenation and ventilation and reduce work of breathing, breathing frequency, and the need for intubation. The precise mechanisms by which physiologic parameters are improved with HFNC are unknown, but may be related to increases in PEEP and $\mathrm{CO}_{2}$ elimination from the anatomic nasopharyngeal airways. Currently, there is no consensus on initial flow for a given patient size, weaning, or indications for other forms of respiratory support.

\section{What this paper contributes to our knowledge}

These data show direct associations between HFNC flow, PEEP, and ventilation across a range of patient ages. PEEP increased with flow and varied between open- and closed-mouth conditions and the models. Reductions in inspired $\mathrm{CO}_{2}$ levels suggest that purging $\mathrm{CO}_{2}$ from the anatomic dead space is a major contributing factor for improved ventilation in preterm models, whereas disproportionate decreases in inspired $\mathrm{CO}_{2}$ relative to expiratory $\mathrm{CO}_{2}$ imply that $\mathrm{CO}_{2}$ flushing may occur during inhalation and exhalation in all models. The effect of HFNC flow on PEEP and ventilation observed in this study suggests that HFNC support may approximate other forms of noninvasive support.

$\mathrm{CO}_{2}$ sensor $\left(\mathrm{CO}_{2} \mathrm{SMO}\right.$, Philips Respironics, Murrysville, Pennsylvania).

\section{HFNC Systems and Prongs}

Infant and Pediatric Optiflow Junior and Adult Optiflow (Fisher \& Paykel Healthcare, Auckland, New Zealand) and Precision Flow (Vapotherm, Exeter, New Hampshire) HFNC systems were used. Flows were confirmed using a calibrated gas flow analyzer (PF-350, ImtMedical, Buchs, Switzerland) before testing each condition. The HFNC systems were preset at $37^{\circ} \mathrm{C}$ and $\mathrm{F}_{\mathrm{IO}_{2}}$ 1.0. Age-specific flow ranges were chosen based on flows from previously published studies ${ }^{5,25}$ and manufacturer recommendations. HFNC cannula sizing was based on manufacturer recommendations. The prongs were secured in the models' nares to achieve approximately $50 \%$ occlusion (Table 1). The Optiflow HFNC system was set up with an Optiflow Junior heated-wire corrugated breathing circuit (RT329 8-mm outer diameter; pressure relief valve $\sim 40 \mathrm{~cm} \mathrm{H}_{2} \mathrm{O}$ ) for 


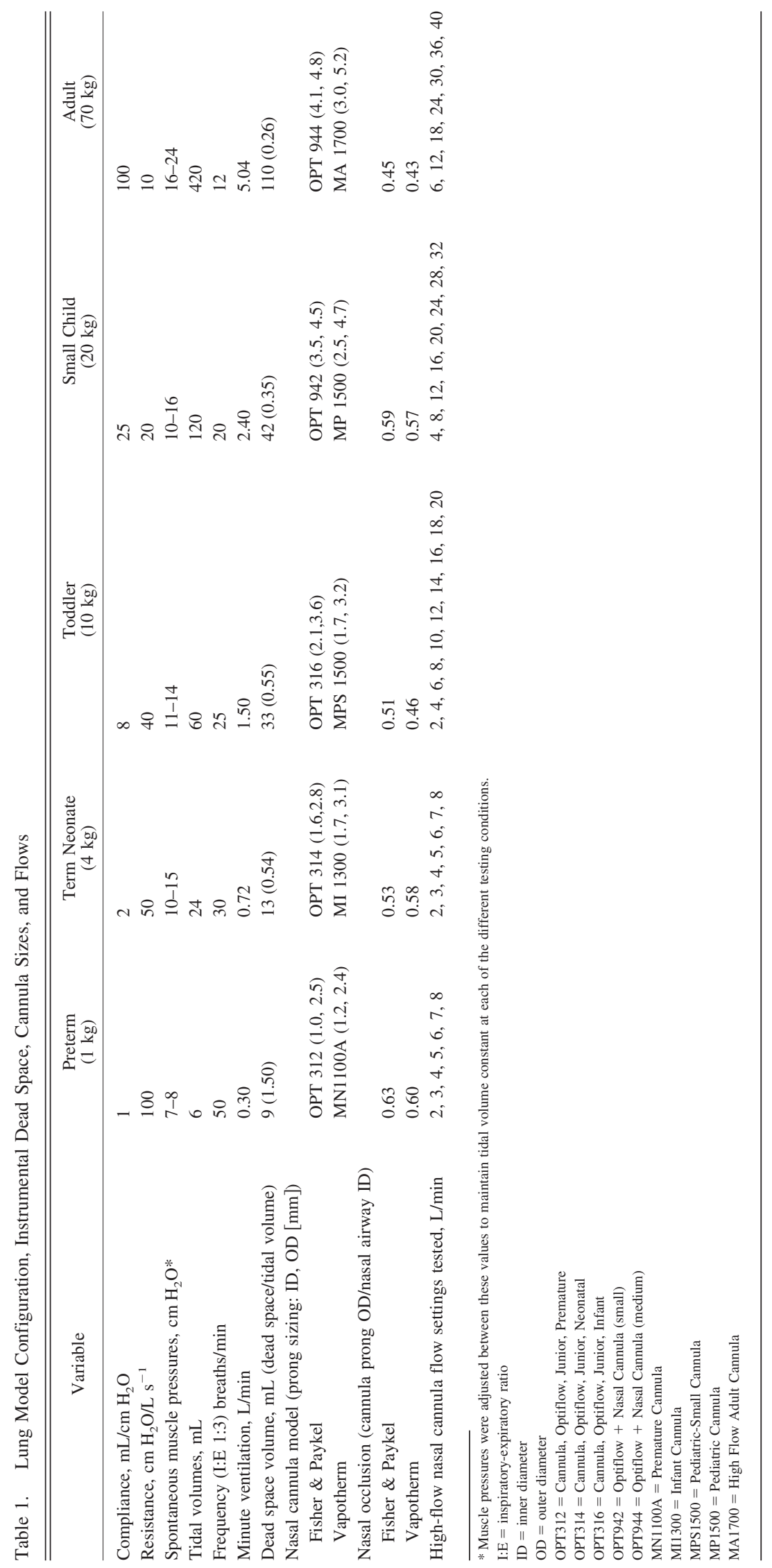




\section{Simulated HFNC EfFects on Expiratory Pressure and Ventilation}

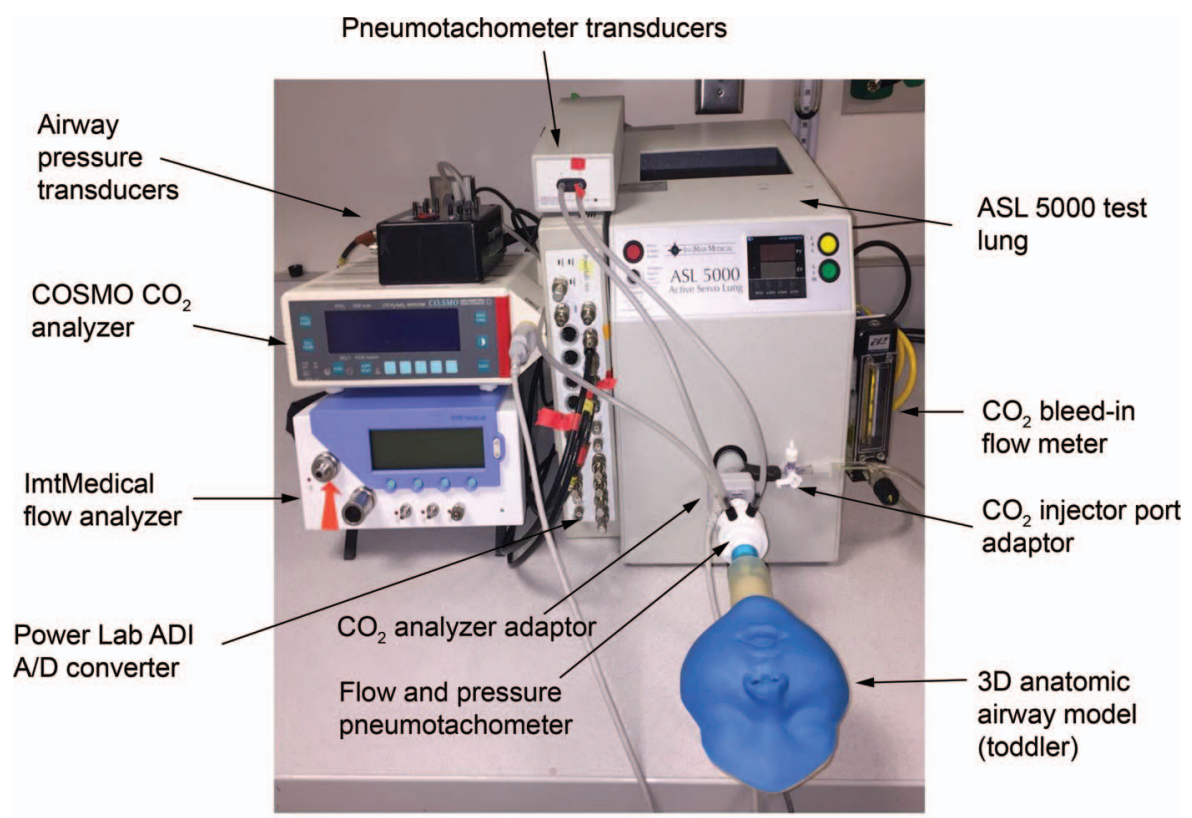

Fig. 1. Experimental setup. Studies were conducted using 5 different 3-dimensional anatomic airway models attached to a spontaneously breathing lung model configured with normal lung mechanics values for each simulated model. The airway model shown is the toddler version. Continuous analogue data were acquired from the individual monitors and lung model, converted with an analogue/digital (A/D) converter, and displayed on a computer monitor (not shown).

infant and toddler models and an adult noninvasive heated-wire corrugated circuit (RT319; 22-mm outer diameter) for small child and adult testing. Both circuits were attached to an MR850 heated humidifier and respective Optiflow or Optiflow Junior cannulae. A standard air/oxygen blender (Bird High Flow, BD Medical, Yorba Linda, California) and an attached oxygen flow rotameter (Cole-Palmer, Vernon Hills, Illinois) were used to adjust flow.

The Precision Flow HFNC system incorporates a standalone user interface module that houses the vapor transfer cartridge, oxygen analyzer, blender, and electronic mass flow sensor. Flow, temperature, and $\mathrm{F}_{\mathrm{IO}_{2}}$ are adjusted independently, and parameters are digitally displayed on the module. The patient circuit incorporates heated water and gas pathways within a smooth-bore patient circuit. A lowflow or high-flow vapor cartridge was used when testing HFNC flows of $1-8$ and 5-40 L/min, respectively. In some cases, vapor cartridge sizing was based on the manufacturer's suggested size per the different cannula sizes.

The resolution of flow measurement with the Precision Flow was 0.5 and $1.0 \mathrm{~L} / \mathrm{min}$ with the high- and low-flow cartridges, respectively. Since the measured flows with the Precision Flow appeared to vary from the preset flow setting on the device, the analog flow meter with the Optiflow was adjusted to match the flow output of the Precision Flow system and confirmed with both systems using a calibrated unidirectional gas flow analyzer before testing at each flow condition.

\section{Experimental Procedures/Data Acquisition}

Each experiment was performed by first random selection of the model, followed by randomized selection of the HFNC system, and then the flow settings were tested in random order. Data were collected in triplicate on 3 separate days for each model and system. Continuous analog output of inspiratory $\mathrm{CO}_{2}$, expiratory $\mathrm{CO}_{2}$, and PEEP were collected from the $\mathrm{CO}_{2} \mathrm{SMOplus}$ monitor and ASL 500 lung model, respectively, and processed using an analogto-digital converter (ADInstruments, Colorado Springs, Colorado). Tracheal flow was measured using a calibrated heated pneumotachometer head (Hans Rudolph, Shawnee, Kansas) and acquired using a PowerLab Spirometer Pod (ADInstruments). All data were displayed and recorded digitally with LabChart 5.5.6 data analysis software (ADInstruments).

$\mathrm{CO}_{2}$ flow into the lung was adjusted to simulate profound hypercapneic respiratory failure with an end-tidal partial pressure of carbon dioxide $\left(\mathrm{P}_{\mathrm{ETCO}_{2}}\right)$ of $90 \pm 1 \mathrm{~mm} \mathrm{Hg}$. Data were inspected in real time, and steady state was determined visually from streaming data. Pressure and ventilation measurements were collected for $1 \mathrm{~min}$ before and $6 \mathrm{~min}$ after cannula placement. Immediately following cannula placement, ASL lung model muscle pressures were adjusted to maintain targeted tidal volumes (Table 1). 


\section{Simulated HFNC Effects on Expiratory Pressure and Ventilation}

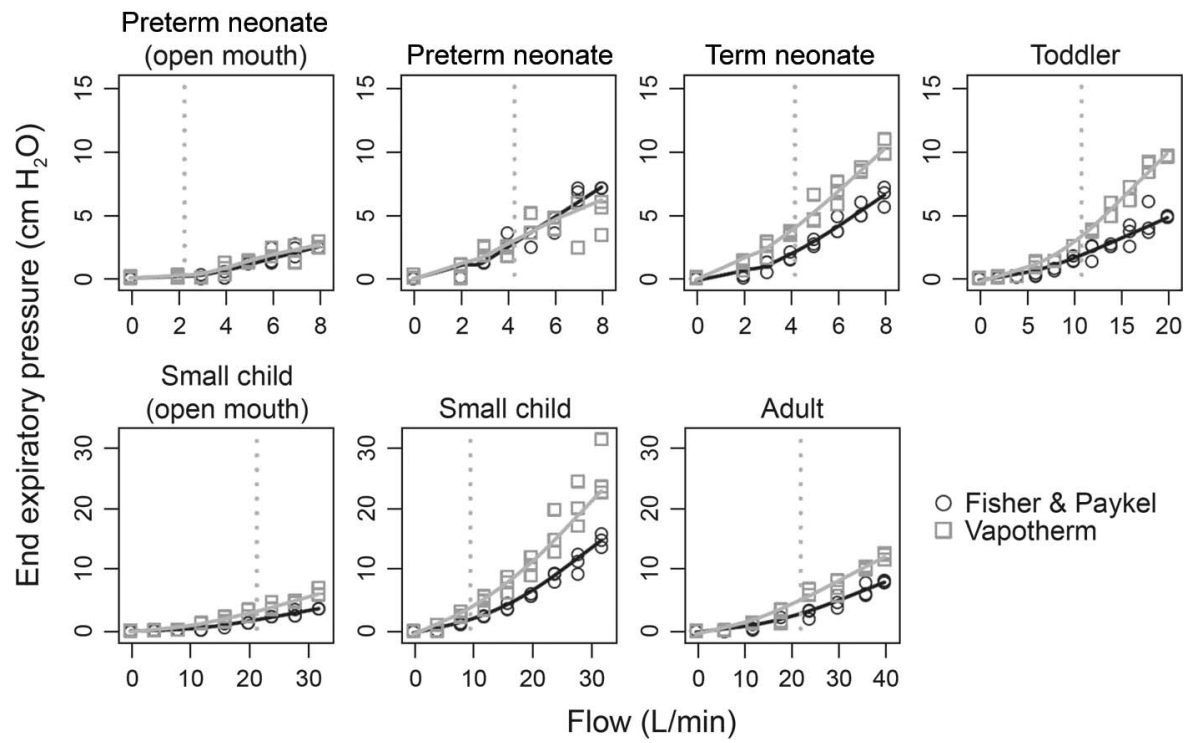

Fig. 2. Lung model end-expiratory pressure or PEEP representing simulated alveolar pressure at baseline (no high-flow nasal cannula) and pressure at different flows provided with the Optiflow and Precision Flow high-flow nasal cannula systems. Individual data points are shown for each measurement of pressure, fitted with locally weighted scatterplot smoothing curves. Gray vertical lines represent the change point where a nonlinear relationship between flow and pressure is observed.

\section{Data Analysis}

Inspiratory $\mathrm{CO}_{2}$ was determined as the measured $\mathrm{CO}_{2}$ at peak inspiratory flow, whereas expiratory $\mathrm{CO}_{2}$ (also known as $\mathrm{P}_{\mathrm{ETCO}_{2}}$ ) and PEEP were measured at zero flow at end expiration. Inspiratory $\mathrm{CO}_{2}$ values represented exhaled $\mathrm{CO}_{2}$ that was rebreathed from the airway model (dead space), whereas expiratory $\mathrm{CO}_{2}$ values represented simulated alveolar $\mathrm{CO}_{2}$ from the lung model. Baseline and response variables for each signal were determined by the arithmetic means of measurements acquired during the $1 \mathrm{~min}$ preceding and 5th minute following cannula placement, respectively. Data were analyzed using random-intercept linear mixed-effects models; segmented linear mixed-effects models with fixed effects for both the change point and the slope differences before and after the change point were used when data indicated a nonlinear relationship between flow and signal. All data were analyzed in $\mathrm{R}$ (v.3.4.1, R Foundation for Statistical Computing, Vienna, Austria). ${ }^{26,27}$ Piece-wise linear dependence was observed between PEEP and flow, so segmented random-intercept linear mixed-effects models were fitted with fixed effects for both the change point and the slope differences before and after the change point. PEEP data were right-skewed, so the analysis was performed on the log scale. Model results are reported as the estimated change point and the mean percentage increase with $95 \%$ CIs for each unit increase in flow below and above the change point.

All analyses were done separately for each model. First, $\mathrm{P}_{\mathrm{ETCO}_{2}}$ and inspired $\mathrm{CO}_{2}$ at the minimum tested flow were compared with baseline using summary statistics and linear mixed-effects models with a random intercept for the experimental day. Model results are reported as mean difference \pm SE of the difference between the 2 flows. Separate analyses were performed for positive flows. There, signal variations were modeled as a function of flow using random-intercept linear mixed-effects models. Where piece-wise linear dependence was observed, segmented random-intercept linear mixed-effects models were fitted with fixed effects for both the change point and the slope differences before and after the change point. In segmented linear mixed-effects models, change points were estimated iteratively and simultaneously with other parameters. Residual analyses were performed using summary and graphical statistics. Model results are reported as the mean change in response for a $1-\mathrm{L} / \mathrm{min}$ increase in flow below and above the change point.

\section{Results}

There was a nonlinear increase in PEEP as a function of HFNC flow in all models (Fig. 2). The rate of increase was greater at flows below the change point than above the change point in all models except for the preterm openmouth model (Table 2). The change point increased with age from $4 \mathrm{~L} / \mathrm{min}$ in the preterm and term neonates to $10 \mathrm{~L} / \mathrm{min}$ in the toddler and small child to $22 \mathrm{~L} / \mathrm{min}$ in the adult (Table 2). The flow required to generate a PEEP of $6 \mathrm{~cm} \mathrm{H} \mathrm{H}_{2} \mathrm{O}$ also increased with age: preterm neonate, $8 \mathrm{~L} / \mathrm{min}$; term neonate, $5-7 \mathrm{~L} / \mathrm{min}$; toddler, $14-20 \mathrm{~L} / \mathrm{min}$; 


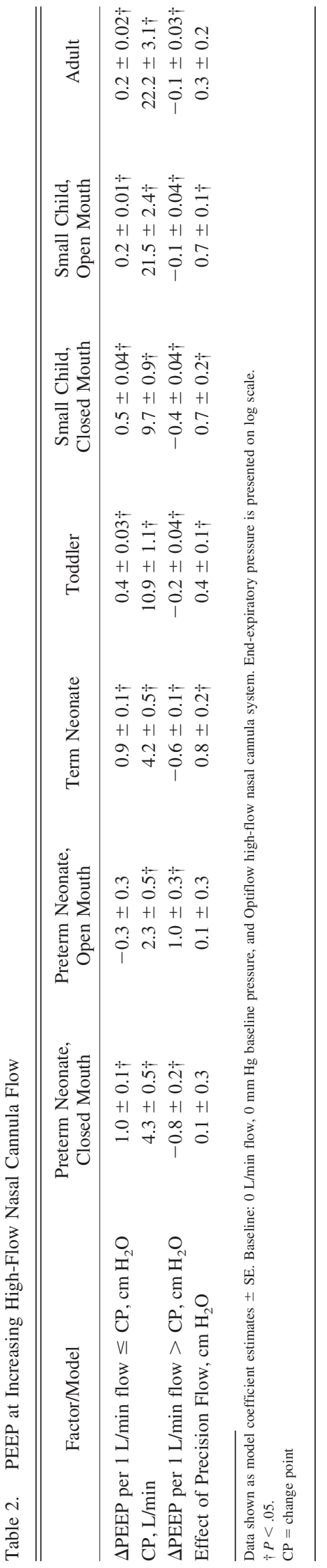

small child, 12-20 L/min; adult, 24-36 L/min. The Precision Flow system generated higher PEEPs than the Optiflow system in the term neonate, toddler, and small child models (Fig. 2 and Table 2).

Expiratory $\mathrm{CO}_{2}$ clearance increased from baseline at the minimum tested flow in all models (Table 3 ). The relationships between expiratory $\mathrm{CO}_{2}$ and flow were linear in the term-neonate and adult models and approximately piece-wise linear in all other models (Fig. 3). The estimated change point for $\mathrm{CO}_{2}$ clearance increased with age. The average decrease in expiratory $\mathrm{CO}_{2}$ per $1-\mathrm{L} / \mathrm{min}$ increase in flow was greatest between baseline and the minimum tested flow. There was no difference in expiratory $\mathrm{CO}_{2}$ clearance between HFNC systems across all testing conditions (Table 3 ).

Inspiratory $\mathrm{CO}_{2}$ decreased as HFNC flow increased, but the magnitude was less than that observed with expiratory $\mathrm{CO}_{2}$ (Fig. 4). The greatest absolute decrease in inspiratory $\mathrm{CO}_{2}$ per 1-L/min increase in flow was in the preterm neonate between baseline and the minimum tested flow (Table 4). Non-linear relationships between flow and inspiratory $\mathrm{CO}_{2}$ were observed in the preterm neonate, term neonate, and toddler models, with a change point of $5 \mathrm{~L} / \mathrm{min}$. There was minimal to no clinically relevant change in inspiratory $\mathrm{CO}_{2}$ in the adult and small-child models. There was no difference in inspiratory $\mathrm{CO}_{2}$ clearance between HFNC systems (Table 4).

An oral leak decreased the PEEP response to flow by approximately 50\% at the maximum tested flow (Fig. 2). In open-mouth models, both the decrease in expiratory $\mathrm{CO}_{2}$ at minimum tested flow from baseline and the change point estimate were larger than in the corresponding closedmouth models (Fig. 3 and Table 3). The magnitude of decrease in inspiratory $\mathrm{CO}_{2}$ at minimum tested flow was larger in open-mouth versus closed-mouth models (Fig. 4 and Table 4).

\section{Discussion}

These are the first data using realistic airway and lung models to show associations between HFNC flow, PEEP, and ventilation across a range of patient ages. Our major finding is that HFNC provided PEEP similar to those used with CPAP, but only at certain flows in closedmouth models. Increasing HFNC flow improved $\mathrm{CO}_{2}$ elimination, but only to a certain point, above which continued increases in flow had no additional effect. These findings may help clinicians define optimal HFNC settings, inform management guidelines, and help in designing future studies for pediatric patients with respiratory failure.

A recent meta-analysis showed similar rates of survival and bronchopulmonary dysplasia in premature infants supported with nasal CPAP and HFNC, ${ }^{1}$ which may be re- 


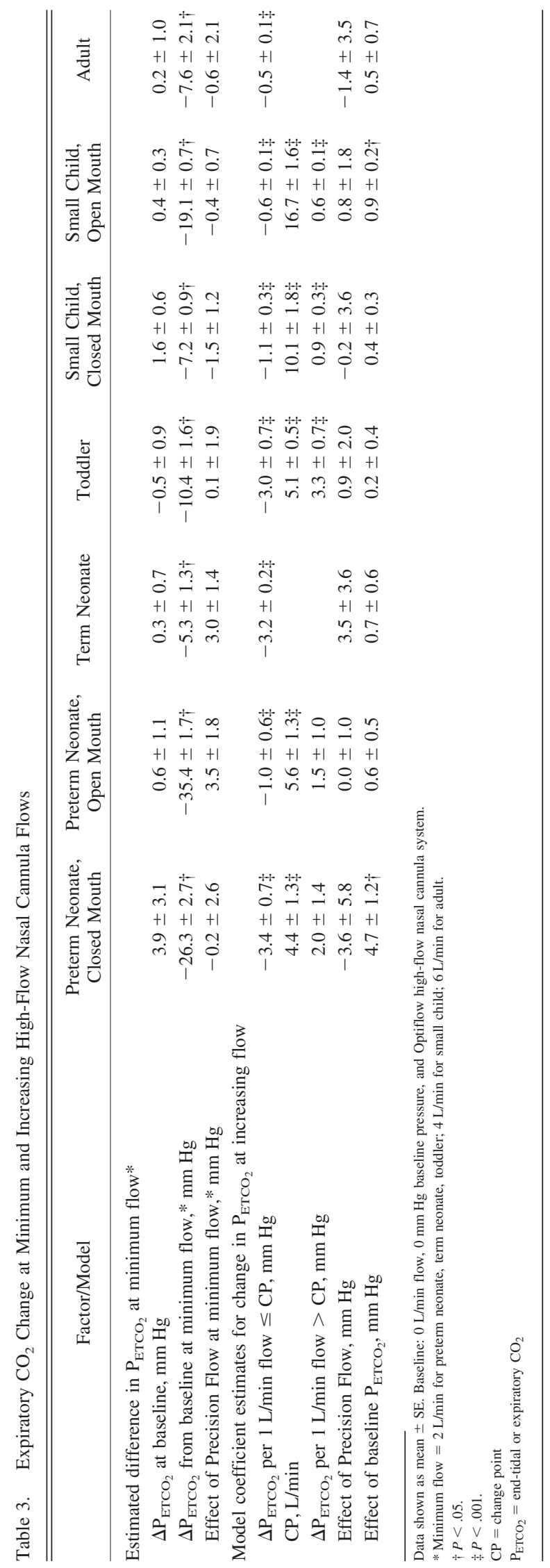

lated to similarities in effective PEEP. One study showed that HFNC increased both PEEP and end-expiratory lung volume, providing evidence that HFNC can recruit collapsed alveoli. ${ }^{28}$ The PEEPs observed in our models correlate well with those reported in infants ${ }^{1,28,29}$ and adults, ${ }^{11,30-32}$ with the exception of 2 studies using adult nasopharyngeal models ${ }^{9,33}$ that we attribute to model differences. Thus, the current study contributes to the growing body of evidence that HFNC generates PEEP.

With HFNC's nonocclusive interface, it is essential to consider the effect of an open mouth, as pressure decreases with an oral leak. ${ }^{34} \mathrm{We}$ observed a 50\% decrease in PEEP with an open mouth. Luo et $\mathrm{al}^{9}$ recently reported nearly absent PEEP in their open-mouth model, suggesting that strategies to close the mouth may benefit patients with disease processes requiring higher PEEP. However, our data also suggest that PEEP rapidly rises to $>10 \mathrm{~cm} \mathrm{H}_{2} \mathrm{O}$ in the small child treated with $\geq 20 \mathrm{~L} / \mathrm{min}$ with a closed mouth. As such, clinicians must recognize the high level and potentially injurious support that can be administered by HFNC when the patient's mouth is closed. Although these findings differ from one study in premature infants, ${ }^{1}$ open-mouth pressures in our preterm neonate model approximate distending pressures observed in premature infants receiving HFNC and nasal CPAP, $6 \mathrm{~cm} \mathrm{H}_{2} \mathrm{O} .{ }^{35}$ Two adult studies ${ }^{30,31}$ and one lung and airway model study ${ }^{9}$ also support our results, reporting a substantial loss of pressure with an oral leak.

Another notable finding was the difference in PEEP generated by the 2 HFNC systems. The higher PEEP with the Precision Flow system is consistent with a previous neonatal bench study. ${ }^{34}$ These differences could be related to the integrated pressure-relief valve in the Optiflow system, which has been shown to vent flow to the atmosphere. ${ }^{36}$ Importantly, the previous studies used first generation Optiflow HFNC prongs rather than the Optiflow Junior. Although the current Optiflow HFNC system still incorporates the pressure-relief valve, the Optiflow Junior cannula's decreased resistance reduces venting of flow to the atmosphere. Another possible explanation for PEEP differences could be increased nasal airway occlusion with the Precision Flow cannulae. This could explain differences in the term neonate; however, the Precision Flow cannula was less occlusive in the toddler and small child models in which greater PEEP was generated at maximum flows. An additional explanation could be differences in prong design, tubing diameter, and relative resistance within the systems. Optiflow cannulae have independent flow channels to each prong and wider bore tubing, whereas the Precision Flow cannulae have a common flow channel and narrower tubing. Three-dimensional computational fluid dynamic models have shown that smaller bore cannulae may produce a higher flow velocity, ${ }^{37}$ and we speculate that a similar phenomenon occurs with the Precision Flow cannulae. 


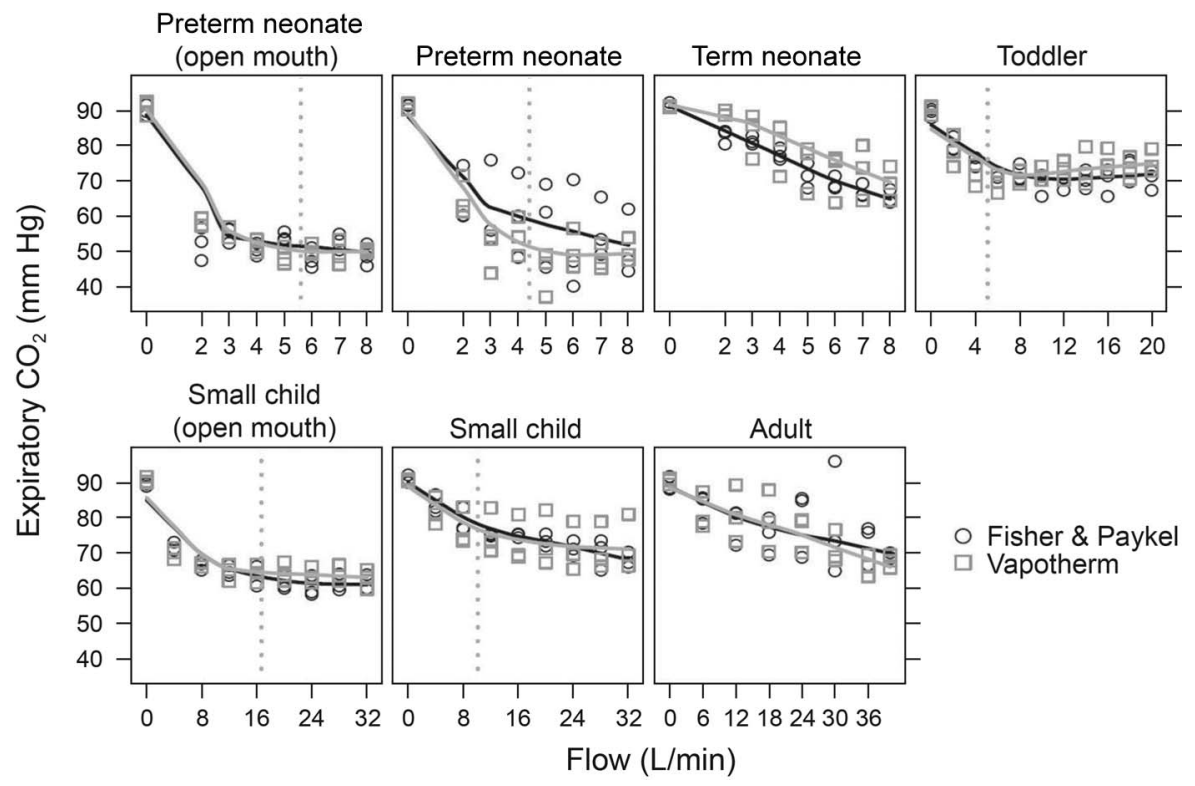

Fig. 3. Lung model expiratory $\mathrm{CO}_{2}$ (or PETOv $)$ representing simulated alveolar $\mathrm{CO}_{2}$ at baseline (no high-flow nasal cannula) and effect on expiratory $\mathrm{CO}_{2}$ at different flows provided with the Optiflow and Precision Flow high-flow nasal cannula systems. Individual data points are shown for each measurement of $\mathrm{CO}_{2}$, fitted with locally weighted scatterplot smoothing curves. Gray vertical lines represent the change point where a nonlinear relationship between flow and expiratory $\mathrm{CO}_{2}$ was observed. There was no change point observed in expiratory $\mathrm{CO}_{2}$ in adult and term newborn models.

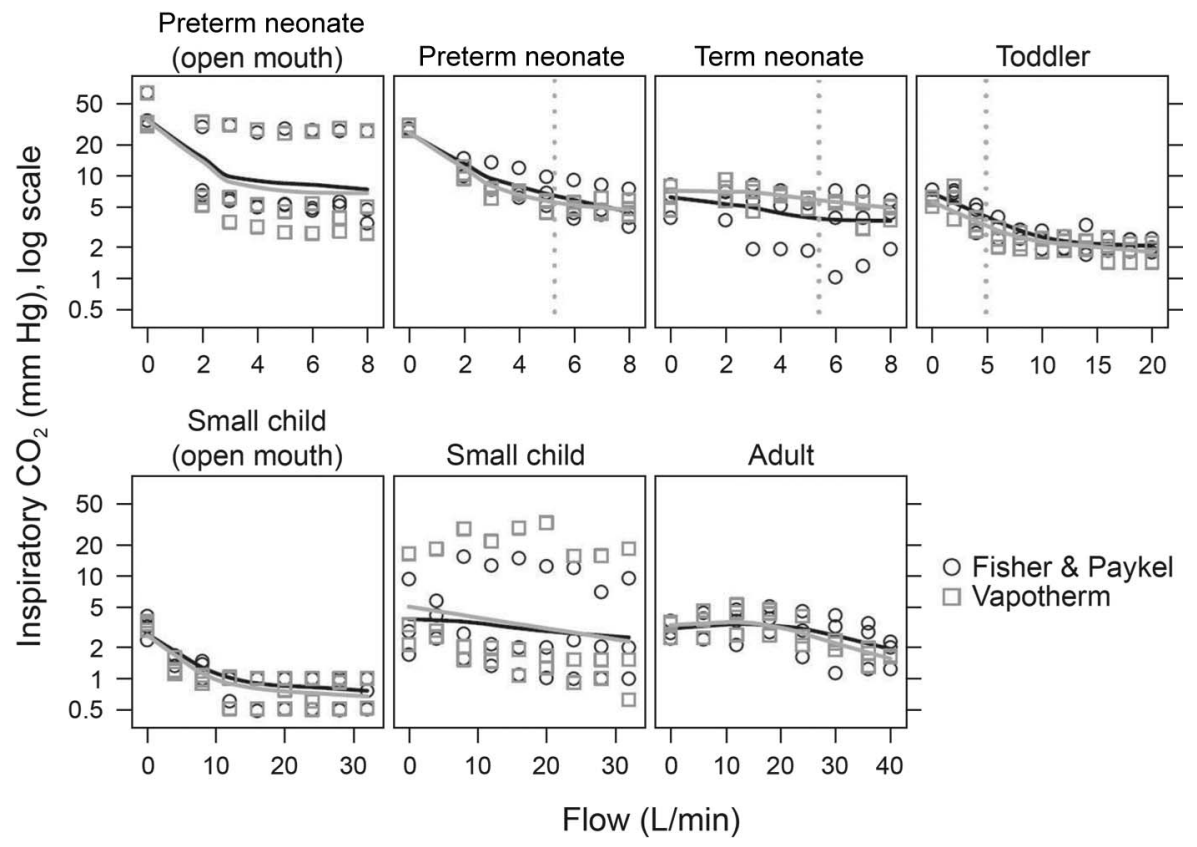

Fig. 4. Lung model inspiratory $\mathrm{CO}_{2}$ representing simulated inspired $\mathrm{CO}_{2}$ from the anatomic airway dead space at baseline (no high-flow nasal cannula) and effect on inspired $\mathrm{CO}_{2}$ at different flows provided with the Optiflow and Precision Flow HFNC systems. Individual data points are shown for each measurement of $\mathrm{CO}_{2}$, fitted with locally weighted scatterplot smoothing curves. Grey vertical lines represent the change point where a nonlinear relationship between flow and inspiratory $\mathrm{CO}_{2}$ was observed. The change point was present only in preterm and term newborn and toddler closed-mouth models.

Improved $\mathrm{CO}_{2}$ clearance with $\mathrm{HFNC}$ helps explain reported clinical reductions in breathing frequency, arterial $\mathrm{CO}_{2}$, and work of breathing in patients treated with HFNC. ${ }^{38}$
One study using tracer gases demonstrated improved $\mathrm{CO}_{2}$ clearance when HFNC flows exceeded peak expiratory flow. ${ }^{39}$ The decrease in expiratory $\mathrm{CO}_{2}$ appears to be due, 


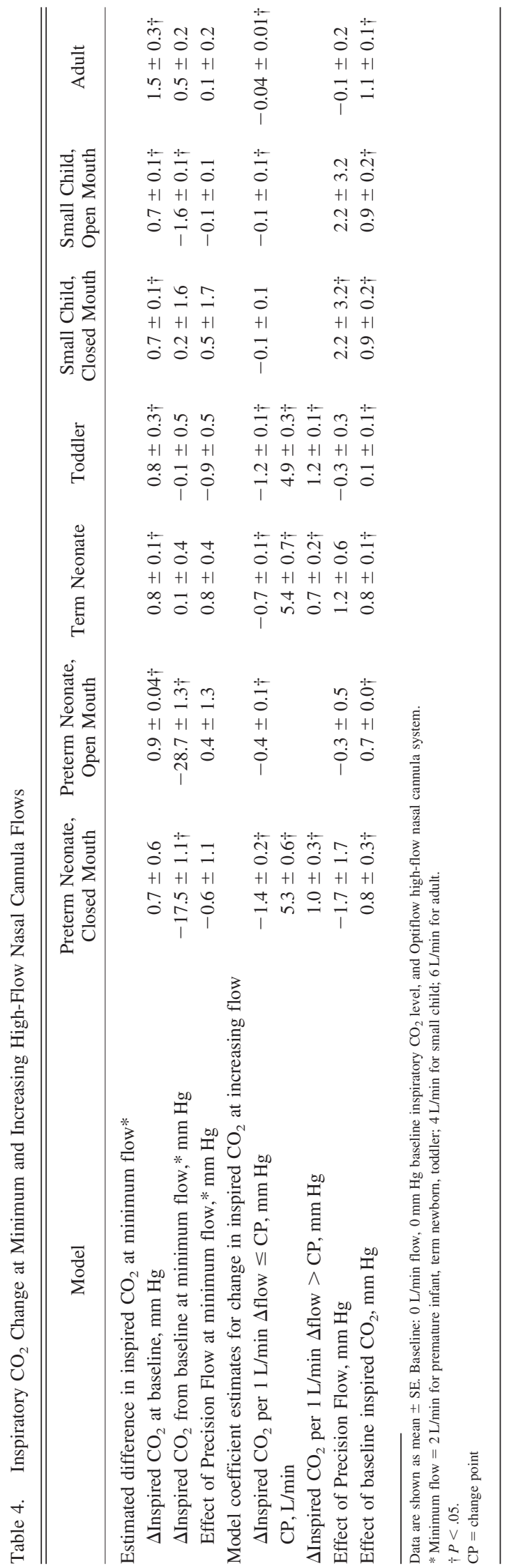

in part, to an immediate reduction in inspired $\mathrm{CO}_{2}$, which was also observed in a tracheotomized adult supported with HFNC. ${ }^{40}$ Similar to prior reports, ${ }^{10,31,41} \mathrm{CO}_{2}$ clearance was more pronounced with an oral leak. These data and previous studies suggest that flushing anatomic dead space with fresh gas is an important mechanism by which HFNC reduces minute ventilation demands. Our results suggest age-dependent differences in the effect of flow on minute ventilation that are explained by the reduction in dead space fraction $\left(\mathrm{V}_{\mathrm{D}} / \mathrm{V}_{\mathrm{T}}\right)$ with increasing age.

The disproportionate decrease in inspired $\mathrm{CO}_{2}$ relative to expiratory $\mathrm{CO}_{2}$ implies that $\mathrm{CO}_{2}$ flushing may occur during inhalation and exhalation. This combined inspiratory/expiratory purging effect may be more pronounced with flows exceeding peak inspiratory flow, which could explain the observed change point in exhaled $\mathrm{CO}_{2}$ clearance. Assuming an extrathoracic volume of $9 \mathrm{~mL}$, tidal volume of $6 \mathrm{~mL}$, and inspiratory time of $0.28 \mathrm{~s}$, the calculated peak inspiratory flow of $3.2 \mathrm{~L} / \mathrm{min}$ approximates the observed change point in our preterm neonate model, implying that higher flows allow $\mathrm{CO}_{2}$ clearance around the nasal cannula during inspiration. Since the adult model showed minimal decrease in inhaled $\mathrm{CO}_{2}$, we assume that linear reductions in exhaled $\mathrm{CO}_{2}$ are related more to flushing during inhalation than exhalation.

Although this study simulated patients in hypercapneic respiratory failure, there are limitations. The anatomic models are based on CT images but lack the mucosal layer and upper-airway elasticity that may affect pressure and airway resistance. The test lung model is unable to simulate atelectasis; hence, generation of PEEP does not recruit alveoli, decreases physiologic dead space and improves ventilation-perfusion matching. Thus, reductions in expiratory $\mathrm{CO}_{2}$ can only be attributable to effects on anatomic dead space. We also used age-appropriate normal lung mechanics rather than a pathophysiologic state in which HFNC would be used, making it challenging to extrapolate our results to clinical use. One of the greatest shortcomings was the variation in cannula placement, resulting in increased variability in measurements. Although markers were used to improve consistency, placing a cannula in the exact position every run proved challenging. However, this probably represents realworld conditions in which cannula position changes with patient positional changes.

We originally intended to completely randomize data collection for each model, HFNC system, and flow to minimize variability due to experimental conditions on a particular day. However, the time required to set up each model and HFNC system made this design impractical. Hence, we opted for randomizing flows within each experimental day. With this design, we observed a systematic bias in ventilation variables associated with the day of collection in some models. Given the employed random- 


\section{Simulated HFNC Effects on Expiratory Pressure and Ventilation}

ization scheme, a linear mixed-effect model with a random intercept was used to account for the effect of the acquisition day.

\section{Conclusions}

Despite these limitations, the observed associations between HFNC flow, PEEP, and ventilation across a wide range of patient sizes contribute to improved understanding of the effects of HFNC. The effect of HFNC flow on PEEP and ventilation observed in this study suggests that HFNC support may approximate other forms of noninvasive support. Studies in infants ${ }^{42}$ and adults ${ }^{43}$ have shown that HFNC is potentially as effective as noninvasive ventilation in preventing invasive ventilation, so its use may result in decreased morbidity associated with invasive ventilation. Although our findings may serve as a guide for clinicians using HFNC, clinical studies to delineate HFNC effects in children and adults are necessary to determine whether these findings hold true.

\section{REFERENCES}

1. Wilkinson D, Andersen C, O'Donnell CPF, De Paoli AG, Manley BJ. High flow nasal cannula for respiratory support in preterm infants. Cochrane Database Syst Rev 2016;(2):CD006405.

2. Beggs S, Wong ZH, Kaul S, Ogden KJ, Walters JAE. High-flow nasal cannula therapy for infants with bronchiolitis. Cochrane Database Syst Rev 2014(1):CD009609.

3. Nishimura M. High-flow nasal cannula oxygen therapy in adults: physiological benefits, indication, clinical benefits, and adverse effects. Respir Care 2016;61(4):529-541.

4. Messika J, Ben Ahmed K, Gaudry S, Miguel-Montanes R, Rafat C, Sztrymf B, et al. Use of high-flow nasal cannula oxygen therapy in subjects with ARDS: a 1-year observational study. Respir Care 2015; 60(2):162-169.

5. Frat JP, Thille AW, Mercat A, Girault C, Ragot S, Perbet S, et al. High-flow oxygen through nasal cannula in acute hypoxemic respiratory failure. N Engl J Med 2015;372(23):2185-2196.

6. Collins CL, Holberton JR, Barfield C, Davis PG. A randomized controlled trial to compare heated humidified high-flow nasal cannulae with nasal continuous positive airway pressure postextubation in premature infants. J Pediatr 2013;162(5):949-954.e1.

7. Metge P, Grimaldi C, Hassid S, Thomachot L, Loundou A, Martin C, Michel F. Comparison of a high-flow humidified nasal cannula to nasal continuous positive airway pressure in children with acute bronchiolitis: experience in a pediatric intensive care unit. Eur J Pediatr 2014;173(7):953-958.

8. Sim MA, Dean P, Kinsella J, Black R, Carter R, Hughes M. Performance of oxygen delivery devices when the breathing pattern of respiratory failure is simulated. Anaesthesia 2008;63(9):938-940.

9. Luo JC, Lu MS, Zhao ZH, Jiang W, Xu B, Weng L, et al. Positive End-Expiratory pressure effect of 3 high-flow nasal cannula devices. Respir Care 2017;62(7):888-895.

10. Frizzola M, Miller TL, Rodriguez ME, Zhu Y, Rojas J, Hesek A, et al. High-flow nasal cannula: impact on oxygenation and ventilation in an acute lung injury model. Pediatr Pulmonol 2011;46(1):6774.
11. Parke RL, Bloch A, McGuinness SP. Effect of very-high-flow nasal therapy on airway pressure and end-expiratory lung impedance in healthy volunteers. Respir Care 2015;60(10):1397-1403.

12. Sivieri EM, Gerdes JS, Abbasi S. Effect of HFNC flow rate, cannula size, and nares diameter on generated airway pressures: an in vitro study. Pediatr Pulmonol 2013;48(5):506-514.

13. Vargas F, Saint-Leger M, Boyer A, Bui NH, Hilbert G. Physiologic effects of high-flow nasal cannula oxygen in critical care subjects. Respir Care 2015;60(10):1369-1376.

14. Dysart K, Miller TL, Wolfson MR, Shaffer TH. Research in high flow therapy: mechanisms of action. Respir Med 2009;103(10):14001405.

15. Mauri T, Turrini C, Eronia N, Grasselli G, Volta CA, Bellani G, Pesenti A. Physiologic effects of high-flow nasal cannula in acute hypoxemic respiratory failure. Am J Respir Crit Care Med 2017; 195(9):1207-1215.

16. Youngquist TM, Richardson CP, Diblasi RM. Effects of condensate in the exhalation limb of neonatal circuits on airway pressure during bubble CPAP. Respir Care 2013;58(11):1840-1846.

17. Wu G, Wollen A, DiBlasi RM, Himley S, Saxon E, Austin G, et al. Reservoir cannulas for pediatric oxygen therapy: a proof-of-concept study. Int J Pediatr 2016;2016:9214389.

18. DiBlasi RM, Coppolo DP, Nagel MW, Doyle CC, Avvakoumova VI, Ali RS, Mitchell JP. A novel, versatile valved holding chamber for delivering inhaled medications to neonates and small children: laboratory simulation of delivery options. Respir Care 2010;55(4):419426.

19. Numa AH, Newth CJ. Anatomic dead space in infants and children. J Appl Physiol 1996;80(5):1485-1489.

20. DiBlasi RM, Crotwell DN, Shen S, Zheng J, Fink JB, Yung D. Iloprost drug delivery during infant conventional and high-frequency oscillatory ventilation. Pulm Circ 2016;6(1):63-69.

21. Coffey PS, Saxon EA, Narayanan I, DiBlasi RM. Performance and acceptability of two self-inflating bag-mask neonatal resuscitator designs. Respir Care 2015;60(9):1227-1237.

22. Poli JA, Richardson CP, DiBlasi RM. Volume oscillations delivered to a lung model using 4 different bubble CPAP systems. Respir Care 2015;60(3):371-381.

23. Hsia D, DiBlasi RM, Richardson P, Crotwell D, Debley J, Carter E. The effects of flexible bronchoscopy on mechanical ventilation in a pediatric lung model. Chest 2009;135(1):33-40.

24. Striegl AM, Redding GJ, Diblasi R, Crotwell D, Salyer J, Carter ER. Use of a lung model to assess mechanical in-exsufflator therapy in infants with tracheostomy. Pediatr Pulmonol 2011;46(3):211-217.

25. Franklin D, Dalziel S, Schlapbach LJ, Babl FE, Oakley E, Craig SS, et al. Early high flow nasal cannula therapy in bronchiolitis, a prospective randomised control trial (protocol): a Paediatric Acute Respiratory Intervention Study (PARIS). BMC Pediatr 2015;15:183.

26. R Development Core Team. R: a language and environment for statistical computing. 2008; http://www.r-project.org.

27. Muggeo VM, Atkins DC, Gallop RJ, Dimidjian S. Segmented mixed models with random changepoints: a maximum likelihood approach with application to treatment for depression study. Stat Model Soc 2014;14(4):293-313.

28. Hough JL, Pham TM, Schibler A. Physiologic effect of high-flow nasal cannula in infants with bronchiolitis. Pediatr Crit Care Med 2014;15(5):e214-e219.

29. Urbano J, del Castillo J, López-Herce J, Gallardo JA, Solana MJ, Carrillo Á. High-flow oxygen therapy: pressure analysis in a pediatric airway model. Respir Care 2012;57(5):721-726.

30. Groves N, Tobin A. High flow nasal oxygen generates positive airway pressure in adult volunteers. Aust Crit Care 2007;20(4):126131 


\section{Simulated HFNC Effects on Expiratory Pressure and Ventilation}

31. Ritchie JE, Williams AB, Gerard C, Hockey H. Evaluation of a humidified nasal high-flow oxygen system using oxygraphy, capnography and measurement of upper airway pressures. Anaesth Intensive Care 2011;39(6):1103-1110.

32. Corley A, Caruana LR, Barnett AG, Tronstad O, Fraser JF. Oxygen delivery through high-flow nasal cannulae increase end-expiratory lung volume and reduce respiratory rate in post-cardiac surgical patients. Br J Anaesth 2011;107(6):998-1004.

33. Kumar H, Spence CJ, Tawhai MH. Modeling the pharyngeal pressure during adult nasal high flow therapy. Respir Physiol Neurobiol 2015;219:51-57.

34. Hasan RA, Habib RH. Effects of flow rate and airleak at the nares and mouth opening on positive distending pressure delivery using commercially available high-flow nasal cannula systems: a lung model study. Pediatr Crit Care Med 2011;12(1):e29-e33.

35. Saslow JG, Aghai ZH, Nakhla TA, Hart JJ, Lawrysh R, Stahl GE, Pyon KH. Work of breathing using high-flow nasal cannula in preterm infants. J Perinatol 2006;26(8):476-480.

36. Lampland AL, Plumm B, Meyers PA, Worwa CT, Mammel MC. Observational study of humidified high-flow nasal cannula compared with nasal continuous positive airway pressure. J Pediatr 2009; 154(2):177-182.

37. Miller TL, Saberi B, Saberi S. Computational fluid dynamics modeling of extrathoracic airway flush: evaluation of high flow nasal cannula design elements. J Pulm Respir Med 2016;6(5):1-7. doi: 10.4172/2161-105X.1000376.

38. Jeong JH, Kim DH, Kim SC, Kang C, Lee SH, Kang TS, et al. Changes in arterial blood gases after use of high-flow nasal cannula therapy in the ED. Am J Emerg Med 2015;33(10):1344-1349.

39. Möller W, Celik G, Feng S, Bartenstein P, Meyer G, Oliver E, et al. Nasal high flow clears anatomical dead space in upper airway models. J Appl Physiol 2015;118(12):1525-1532.

40. Fricke K, Tatkov S, Domanski U, Franke KJ, Nilius G, Schneider H. Nasal high flow reduces hypercapnia by clearance of anatomical dead space in a COPD patient. Respir Med Case Rep 2016; 19:115-117.

41. Sivieri EM, Foglia EE, Abbasi S. Carbon dioxide washout during high flow nasal cannula versus nasal CPAP support: an in vitro study. Pediatr Pulmonol 2017:52(6):792-798.

42. Kugelman A, Riskin A, Said W, Shoris I, Mor F, Bader D. A randomized pilot study comparing heated humidified high-flow nasal cannulae with NIPPV for RDS. Pediatr Pulmonol 2015;50(6):576583.

43. Nagata K, Morimoto T, Fujimoto D, Otoshi T, Nakagawa A, Otsuka $\mathrm{K}$, et al. Efficacy of high-flow nasal cannula therapy in acute hypoxemic respiratory failure: decreased use of mechanical ventilation. Respir Care 2015;60(10):1390-1396.

This article is approved for Continuing Respiratory Care Education credit. For information and to obtain your CRCE

(free to AARC members) visit www.rcjournal.com 